\title{
Rheumatoid arthritis in Jordan: a cross sectional study of disease severity and associated comorbidities
}

This article was published in the following Dove Press journal:

Therapeutics and Clinical Risk Management

19 May 2014

Number of times this article has been viewed

\author{
Khaldoon M Alawneh' \\ Basheer Y Khassawneh' \\ Mahmoud H Ayesh' \\ Mahmoud Smadi \\ 'Department of Medicine, \\ College of Medicine, King \\ Abdullah University Hospital, \\ Jordan University of Science and \\ Technology, Irbid, Jordan; \\ ${ }^{2}$ Department of Math and Statistics, \\ College of Science, Jordan University \\ of Science and Technology, \\ Irbid, Jordan
}

\begin{abstract}
Treating rheumatoid arthritis (RA) to target is advocated using disease activity measures. The impact of RA on the general health status of affected patients in Jordan is not well described. This study reported the severity of RA in Jordan and its association with consequent disabilities and comorbidities. A cross-sectional, observational study was conducted at King Abdullah University Hospital in the north of Jordan. All patients who were diagnosed with RA were included. Patients' demographics, comorbidities, disease activity score (DAS 28), and clinical disease activity index (CDAI) were collected. Both DAS 28 and CDAI were utilized to categorize RA disease activity. A total of 465 patients with RA were included: $82 \%$ were females; mean age \pm standard deviation (SD) was $47.62 \pm 14$.6 years; and mean disease duration \pm SD was $6 \pm 4.45$ years. The mean \pm SD for the DAS 28 and CDAI was $5.1 \pm 1.5$ and $23 \pm 14.2$, respectively. According to the DAS $28,51 \%$ of the patients were in the high disease activity category and only 5\% were in remission. On the other hand, according to the CDAI, $44 \%$ were in the high disease activity category and only $1 \%$ were in remission. In Jordan, patients with RA have a high severe disease rate and a low remission rate. The disease is often progressive and associated with comorbidities that need to be managed.
\end{abstract}

Keywords: rheumatoid arthritis, DAS 28, CDAI, Middle East, remission, disabilities

\section{Introduction}

Treating rheumatoid arthritis (RA) has never been an easy task. Recently, treating to target was advocated using RA disease activity measures. ${ }^{1}$ There is evidence that RA in developing countries is not a mild disease and may result in disabilities. ${ }^{2}$ In Jordan, there is a lack of published evidence of impact of RA on the affected patient's health. However, RA management is still performed based on personal preference with no clearly defined targets and with no national guidelines. In this work we stress the importance of treating RA to target to prevent complications and disabilities. Furthermore, we advocate that management of comorbidities should be part of an RA treatment plan which works overall to affect the final outcome.The objectives of this study were to report the severity of RA in Jordan and to describe the association with disease related disabilities and comorbidities.

\section{Methodology}

This was a cross-sectional, observational study that was conducted at King Abdullah University Hospital (Irbid, Jordan) between January and December 2012. The study included patients who were diagnosed with RA according to the 1987 revised American College of Rheumatology classification criteria. ${ }^{3}$ Data were collected on
Department of Medicine, College of Medicine, King Abdullah University Hospital, Jordan University of Science and Technology, PO Box 3030, Irbid, Jordan 22110

Email kmal234@msn.com
Therapeutics and Clinical Risk Management 20I4:10 363-366 
active patients with RA and those who visited the rheumatology clinic during the study period. Collected data included: patients' demographics; duration of the disease; presence of comorbidities and disease related disabilities; and active RA-related medications. During the same routine clinical visit, the number of swollen joints, the number of tender joints, and pain score were documented. Collected data also included disease activity score (DAS 28) and clinical disease activity index (CDAI).

Patients were then stratified into four categories according to DAS 28 and CDAI scores. Remission was categorized as DAS $28 \leq 2.6$ or CDAI $\leq 2.8$; low disease activity was categorized as $\leq 3.2$ for DAS 28 or $\leq 10$ for CDAI; moderate disease activity as $\leq 5.1$ for DAS 28 or $\leq 22$ for CDAI; high disease activity as $>5.1$ for DAS 28 or $>22$ for CDAI. ${ }^{4}$

The data set represented the two dependent variables DAS 28 and CDAI, and the set of predictors included age, sex, rheumatoid factor (RF) positivity, obesity (body mass index $[\mathrm{BMI}] \geq 30 \mathrm{~kg} / \mathrm{m}^{2}$ ), RA-related medications, and the presence of comorbidities. Medications included in the analysis included oral prednisolone, methotrexate, and anti-tumor necrosis factor (TNF) agents. Comorbidities included hypertension, diabetes mellitus, and osteoporosis. Summary statistics such as means and standard deviations of quantitative variables were calculated. Frequencies and percentages of factors influencing RA disease severity scores were given. Chi-square test was used to study the association among the categories of both DAS 28 and CDAI.

Multivariate analysis of variance (MANOVA) using the general linear model (GLM) procedure was used to analyze and examine the significant continuous and categorical predictors on DAS 28 and CDAI for all patients. MANOVA also provided separate results for each of the dependent variables - DAS 28 and CDAI - separately. A $P$-value of less than 0.05 was considered statistically significant. Statistical Package for Social Sciences (SPSS Statistics, version 17; SPSS Inc., Chicago, IL, USA) was used to perform the statistical analysis. The study was approved by the Institutional Review Board of Jordan University of Science and Technology and King Abdullah University Hospital in the north of Jordan.

\section{Results}

A total of 465 patients with RA were included in the study. The mean age was 47.6 years (range 15 to 84 years) and $82 \%$ were female. Mean \pm standard deviation (SD) BMI was $29.4 \pm 5.97 \mathrm{~kg} / \mathrm{m}^{2}$ (in the overweight range). The average duration of disease was 6 years (range 1-34 years). Rheumatoid factor was positive in $50 \%$ of the patients. Half of the patients (241 patients) were on oral prednisolone, 300 patients (71\%) were on oral methotrexate, and 110 patients $(24 \%)$ were on anti-TNF medications.

The mean $\pm \mathrm{SD}$ dose for oral prednisolone was $3.17 \pm 3.66 \mathrm{mg} /$ day, while for methotrexate this was $11.63 \pm 8.44 \mathrm{mg} /$ day. Diabetes mellitus (DM) was documented in 85 patients $(18.3 \%)$, hypertension in 112 patients $(24 \%)$, and osteoporosis in 85 patients (18.3\%). Obesity (BMI $\geq 30 \mathrm{~kg} / \mathrm{m}^{2}$ ) was present in 157 patients (34\%). Joint damage was documented in 158 patients (34\%), and 37 patients $(8 \%)$ had joint replacement.

The mean \pm SD for DAS 28 was $5.10 \pm 1.5$ and for CDAI was $23.46 \pm 14.2$; both were in the high disease activity category range. According to the DAS 28, 51\% were in the high disease activity category and only $5 \%$ were in remission. Similarly, according to the CDAI, $44 \%$ were in the high disease activity category and only $1 \%$ were in remission. Details and cross tabulation between the two disease activity measures (DAS 28 and CDAI) are given in Table 1. Both DAS 28 and CDAI correlated with disease activity for the same clinic visit, $P$-value $<0.001$. In addition, the Pearson's correlation coefficient between DAS 28 and CDAI was significant $(r=0.89)$.

Using MANOVA of the two dependent variables (DAS 28 and CDAI), the Pillai's trace test showed the following significant predictors of poor control of the disease: use

Table I Cross-tabulation of both disease activity scores (DAS 28 and CDAI)

\begin{tabular}{|c|c|c|c|c|c|}
\hline \multirow[t]{2}{*}{ Disease activity } & \multicolumn{5}{|l|}{ CDAI } \\
\hline & High & Moderate & Low & Remission & Total \\
\hline \multicolumn{6}{|l|}{ DAS 28} \\
\hline High & 187 & 48 & 0 & 0 & 235 (5I\%) \\
\hline Moderate & 15 & 114 & 42 & 0 & $17 \mid$ (37\%) \\
\hline Low & 2 & 4 & 24 & 0 & 30 (7\%) \\
\hline Remission & 0 & I & 17 & 6 & $24(5 \%)$ \\
\hline Total & 204 (44\%) & 167 (36\%) & 83 (I8\%) & $6(1 \%)$ & 460 \\
\hline
\end{tabular}

Abbreviations: DAS 28, disease activity score; CDAl, clinical disease activity index. 
of anti-TNF agents $(P=0.009)$; use of oral prednisolone $(P<0.001)$; and female sex $(P<0.001)$.

MANOVA was also used to provide a separate analysis of variance for each dependent variable (DAS 28 and CDAI). The results for the DAS 28 showed the following significant predictors: use of anti-TNF agents $(P=0.036)$; female sex $(P=0.003)$; and use of oral prednisolone $(P<0.001)$. For the CDAI, the following were significant predictors of poor control: use of anti-TNF agents $(P=0.004)$; and use of oral prednisolone $(P<0.001)$.

\section{Discussion}

This study showed that RA in Jordan is a rather severe disease, as most patients are in the high or moderate disease category ( $88 \%$ ). In addition, only $5 \%$ were in remission, despite being established patients in a rheumatology specialty clinic and being actively treated with disease modifying drugs, including anti-TNF agents. Regional data from the United Arab Emirates were similar to our findings. ${ }^{5}$ Badsha et $\mathrm{al}^{5}$ reported patients from the United Arab Emirates to have a mean DAS 28 of 5.2, and $12 \%$ of their patients were in the low disease activity or remission categories. In another regional study by Lutf et al, ${ }^{6}$ findings were different from our study in a heterogeneous group of patients with RA. Their mean DAS 28 was $2.85,49 \%$ were in remission, and an additional $15 \%$ were in the low disease activity category. ${ }^{6}$

In Western populations, the mean DAS 28 was similar to our findings. ${ }^{7,8}$ In the ESPOIR (Étude et Suivi des PO1yarthrites Indifférenciées Récentes) cohort routine care arm, the mean DAS 28 was 5.1 but the remission rate was much higher $(30 \%)$ than in the present study. ${ }^{7}$ Similarly, a high remission rate was reported in Finland (36\%) and in the USA $(36 \%) .{ }^{8}$ This difference may be explained by the better access to care and availability of more anti-TNF and other biological agents. In Jordan, delayed disease presentation to rheumatology clinics, lack of understanding of RA longterm complications, and the absence of national guidelines to manage RA may be contributing factors to the findings of this study.

The high rate of joint damage and joint replacement may impose additional and significant burden on health care resources.

Comorbidities including obesity, hypertension, and DM were common among our patients. This may limit treatment options and present an additional burden to the patient's overall mortality and morbidity. This association with comorbidities is comparable to that shown in the general population in Jordan. ${ }^{9-11}$ The high prevalence of hypertension in patients with RA was reported to be associated with age, prednisolone use, and high BMI. ${ }^{12}$

Both the DAS 28 score and obesity were previously reported as independently associated with impaired quality of life in patients with RA. ${ }^{13}$ In this studied population, oral prednisolone significantly correlated with RA disease severity scores. This study also showed that female sex correlated with higher disease activity score, a finding that has been previously shown elsewhere. ${ }^{14}$

This study showed that both DAS 28 and CDAI can be used interchangeably to assess disease severity. For clinicians with limited access or delayed access to laboratory results, CDAI can be used without the need for complicated calculation and or waiting for laboratory results. We should consider adapting a simpler disease activity measure like the Rheumatology Assessment Patient Index Data (RAPID3) which is easy, informative, and less time-consuming to conduct, and which has been previously validated. ${ }^{15}$

Although this is the first study to describe RA disease activity utilizing two disease activity scores in Jordan, the study has some limitations. Patients were recruited from a single referral center and patients who were followed by internists and other practitioners were not included. Also, only patients who were actively followed in the rheumatology clinic were recruited. This may imply that patients with milder disease and well-controlled disease have been excluded from the study. Patients had variable insurance coverage and some did not have access to newer and rather expensive treatment options, like anti-TNF agents.

\section{Conclusion}

In Jordan, patients with RA have a high severe disease rate and low remission rates. The disease is progressive and associated with comorbidities that need to be managed. There is a need to increase the awareness and the importance of documenting disease activity scores when treating patients with RA. There is also a need for local guidelines on treating patients with RA to target utilizing disease activity scores.

\section{Disclosure}

The authors report no conflicts of interest in the work.

\section{References}

1. Smolen JS, Aletaha D, Bijlsma JW, et al; T2T Expert Committee. Treating rheumatoid arthritis to target: recommendations of an international task force. Ann Rheum Dis. 2010;69(4):631-637.

2. Kalla AA, Tikly M. Rheumatoid arthritis in the developing world. Best Pract Res ClinRheumatol. 2003;17(5):863-875.

3. Arnett FC, Edworthy SM, Bloch DA, et al. The American Rheumatism Association 1987 revised criteria for the classification of rheumatoid arthritis. Arthritis Rheum. 1988;31(3):315-324. 
4. Aletaha D, Smolen J. The Simplified Disease Activity Index (SDAI) and the Clinical Disease Activity Index (CDAI): a review of their usefulness and validity in rheumatoid arthritis. ClinExpRheumatol. 2005;23(5 Suppl 39): S100-S108.

5. Badsha H, Kong KO, Tak PP. Rheumatoid arthritis in the United Arab Emirates. ClinRheumatol. 2008;27(6):739-742.

6. Lutf A, Poil AR, Hammoudeh M. Characteristics of patients with rheumatoid arthritis in Qatar: a cross-sectional study. Int J Rheum Dis. 2014;17(1):63-65.

7. Combe B, Benessiano J, Berenbaum F, et al. The ESPOIR cohort: a tenyear follow-up of early arthritis in France: methodology and baseline characteristics of the 813 included patients. Joint Bone Spine. 2007;74(5): 440-445.

8. Sokka T, Hetland ML, Mäkinen H, et al; Questionnaires in Standard Monitoring of Patients With Rheumatoid Arthritis Group. Remission and rheumatoid arthritis: data on patients receiving usual care in twenty-four countries. Arthritis Rheum. 2008;58(9):2642-2651.

9. Khader Y, Batieha A, Ajlouni H, El-Khateeb M, Ajlouni K. Obesity in Jordan: prevalence, associated factors, comorbidities, and change in prevalence over ten years. MetabSyndrRelatDisord. 2008;6(2):113-120.
10. Jaddou H, Bateiha A, Ajlouni K. Prevalence, awareness and management of hypertension in a recently urbanised community, eastern Jordan. J Hum Hypertens. 2000;14(8):497-501.

11. Ajlouni K, Khader YS, Batieha A, Ajlouni H, El-Khateeb M. An increase in prevalence of diabetes mellitus in Jordan over 10 years. J Diabetes Complications. 2008;22(5):317-324.

12. Panoulas VF, Douglas KM, Milionis HJ, et al. Prevalence and associations of hypertension and its control in patients with rheumatoid arthritis. Rheumatology (Oxford). 2007;46(9):1477-1482.

13. García-Poma A, Segami MI, Mora CS, et al. Obesity is independently associated with impaired quality of life in patients with rheumatoid arthritis. ClinRheumatol. 2007;26(11):1831-1835.

14. Forslind K, Hafström I, Ahlmén M, Svensson B; BARFOT Study Group. Sex: a major predictor of remission in early rheumatoid arthritis? Ann Rheum Dis. 2007;66(1):46-52.

15. Pincus T. RAPID3, an index of only 3 patient self-report core data set measures, but not ESR, recognizes incomplete responses to methotrexate in usual care of patients with rheumatoid arthritis. Bull HospJt Dis (2013). 2013;71(2):117-120.
Therapeutics and Clinical Risk Management

\section{Publish your work in this journal}

Therapeutics and Clinical Risk Management is an international, peerreviewed journal of clinical therapeutics and risk management, focusing on concise rapid reporting of clinical studies in all therapeutic areas, outcomes, safety, and programs for the effective, safe, and sustained use of medicines. This journal is indexed on PubMed Central, CAS,

\section{Dovepress}

EMBase, Scopus and the Elsevier Bibliographic databases. The manuscript management system is completely online and includes a very quick and fair peer-review system, which is all easy to use. Visit $\mathrm{http} / / / \mathrm{www}$.dovepress.com/testimonials.php to read real quotes from published authors.

Submit your manuscript here: http://www.dovepress.com/therapeutics-and-clinical-risk-management-journal 